Journal of Biotechnology and Strategic Health Research

\author{
Araştırma Makalesi /Research Article
}

http://dergipark.org.tr/tr/pub/bshr

\title{
Erişkin ve Çocuk Yoğun Bakım Ünitelerinde Santral Sinir Sistemi, Kan ve Santral Venöz Kateterle ilişkili Hastane Enfeksiyonu Etkenlerinin Beş Yıllık Analizi
}

\author{
Five-Year Analysis of Central Nervous System, \\ Blood and Nosocomial Infection Factors Associated with Central Venous Catheter in \\ Adult and Pediatric Intensive Care Units
}

(iD) Pınar Şamlıŏlu' ${ }^{1}$, Sabri Atalay ${ }^{2}$

${ }^{1}$ Sağlık Bilimleri Üniversitesi Tepecik Eğitim ve Araştırma Hastanesi Mikrobiyoloji Laboratuvarı ${ }^{2}$ Sağlık Bilimleri Üniversitesi Tepecik Eğitim ve Araştırma Hastanesi Enfeksiyon Hastalıkları Kliniği ORCID ID: Pınar Şamlıŏlu https://orcid.org/0000-0002-8491-7777, Sabri Atalay https://orcid.org/0000-0001-9076-428

^Sorumlu Yazar / Corresponding Author: Pınar Şamlığlu, e-posta / e-mail: psamlioglu@hotmail.com

Geliş Tarihi / Received : 03-06-2021 Kabul Tarihi / Accepted: 29-06-2021 Yayın Tarihi / Online Published: 30-08-2021

Şamlıoğlu P., Atalay S. Erişkin ve Çocuk Yoğun Bakım Ünitelerinde Santral Sinir Sistemi, Kan ve Santral Venöz Kateterle ilişkili Hastane Enfeksiyonu Etkenlerinin Beş Ylllık Analizi, J Biotechnol and Strategic Health Res. 2021;5(2):119-124

\footnotetext{
Özet

Amaç Hastane enfeksiyonları (HE) yüksek morbidite ve mortalite ile seyretmesi nedeniyle özellikle yoğun bakım ünitelerinde (YBÜ) önem kazanmıș enfeksiyonlardır. Hastanede yatıș süresinin uzaması ve tedavi maliyetini arttırması açısından da önemli sağlık sorunlarından biri haline gelmiștir. Hayat kurtarmak amacıyla yapılan invaziv ișlemler (santral venöz kateter vb.) hastane enfeksiyonu gelişim oranlarını artırmaktadır. Bu çalışmada hastanemiz erişkin ve çocuk yoğun bakım ünitelerinde yatan hastalarda santral sinir sistemi, kan ve santral venöz kateterle ilişkili enfeksiyonlara neden olan etkenlerin dağılımının incelenmesi amaçlanmıştır.

Materyal ve Ocak 2016- Aralık 2020 tarihleri arasında hastanemiz yoğun bakımlarında yatan hastalarda gelișen ve hastane enfeksiyonu olarak değerlendirilen Santral sinir sistemi, kan Metod ve santral venöz kateterle ilişkili kan enfeksiyonları, kültüre dayalı surveyans yöntemi ile retrospektif olarak incelendi. Hastane enfeksiyonlarının takibi, kaydı ve incelenmesi enfeksiyon kontrol komitesi tarafindan yürütüldü.

Bulgular Beş yıllık sürede Erișkin Yoğun Bakımlarda 25105, Yenidoğan Yoğun Bakım’da 6066 , Cocuk Yoğun Bakım’da 1745 olmak üzere toplam 32916 hasta retrospektif olarak incelenmiştir. Hastalardan $186(\% 0,6)$ 'sına laboratuvar tarafından doğrulanmış kan kültür enfeksiyonu, $474(\% 1.44)$ 'üne santral venöz kateter enfeksiyonu, 18 (\%0.05)'ine menenjit tanısı konulmuştur. Santral venöz kateter enfeksiyon etkeni olarak sırasıyla C.parapsilosis 116 (\%24.5), K.pneumoniae 98 (\%20.7), Koagülaz Negatif Staflokoklar 48 (\%10.1) saptanmıștır. Menenjit etkeni olarak en sık K.pneumoniae 11 (\%61.1) daha sonra KNS'ler 2(\%11,1) bulunmuștur. Hastane enfeksiyonu olarak değerlendirilen kan kültür sonuçlarında ise sıklık sırasılla KNS 40 (\%21.7), K.pneumoniae 34 (\%18.5) ve C.parapsilosis 18 (\%9.8) bulunmuştur.

Sonuç HE önlemek için düzenli surveyans çalışmaları yapılmalı, gereksiz invaziv işlemlere izin verilmemelidir. Hastane genelinde el hijyeni uyumunun arttırılması, uygunsuz antibiyotik kullanımının önüne geçilmeli, izolasyon önlemlerinin alınmasına dikkat edilmeli, ve aseptik uygulamalara özen gösterilmelidir. Ayrıca enfeksiyon sebebi olan etkenlerin izole edilerek uygun antibiyotik başlanması ve gereksiz antibiyotik kullanımının önlenmesi gerekir

Anahtar Hastane enfeksiyonu, Santral venöz katater, Kan dolaşım enfeksiyonu, Santral sinir sistemi enfeksiyonu

Kelimeler

Özet

Aim Nosocomial infections (NI) are most commonly seen in intensive care units (ICUs), with high morbidity and mortality. It has become one of the important health problems in terms of prolonging hospital stay and increasing the cost of treatment. Invasive procedures performed to save lives (central venous catheters, etc.) increase the rate of nosocomial infection development. In this study, it was aimed to examine the distribution of the causative agents of central nervous system, blood and central venous catheter-related infections in patients hospitalized in adult and pediatric intensive care units of our hospital.

Material and This study was retrospectively analyzed using culture-based surveillance method for central nervous system, blood and central venous catheter-related blood infections that developed in patients

Method hospitalized in our hospital's intensive care units between January 2016 and December 2020 and were considered as hospital infections. The follow-up, recording and examination of nosocomial infections were carried out by the infection control committee.

Results A total of 32916 patients, 25105 in Adult Intensive Care, 6066 in Neonatal Intensive Care, 1745 in Pediatric Intensive Care within a five-year period, were analyzed retrospectively. C.parapsilosis 116 (24.5\%), K.pneumoniae 98 (20.7\%), Coagulase Negative Staflococci 48 (10.1\%) were found as central venous catheter infection agents, respectively. The most common causative agent of meningitis was K.pneumoniae 11 (61.1\%) and then CNS 2 (11.1\%). In the blood culture results evaluated as hospital infection, the most common CNS was 40 (21.7\%), K.pneumoniae 34 (18.5\%) and C.parapsilosis $18(9.8 \%)$

Conclusion Regular surveillance studies should be done to prevent HE, unnecessary invasive procedures should not be allowed. Increasing hand hygiene compliance throughout the hospital, inappropriate use of antibiotics should be avoided, attention should be paid to isolation measures, and attention should be paid to aseptic practices. In addition, the factors that cause infection should be isolated and appropriate antibiotics should be initiated and unnecessary antibiotic use should be prevented.

Keywords Nosocomial infection, Central venous catheter, Blood circulation infection, Central nervous system infection
} 


\section{GíRìş}

Hastane enfeksiyonları (HE) hastaneye yatış öncesinde inkübasyon döneminde olmayan, hastaneye yatıştan 48-72 saat sonra veya taburcu olduktan 10 gün içinde gelişen ayrıca kalıcı cihaz uygulanması durumunda 1 yıl kadar süre içinde ortaya çıkabilen enfeksiyonlardır ${ }^{1}$. HE toplum kaynaklı enfeksiyonlardan daha ağır klinik gidiş gösteren, hastanede kalış süresini uzatan, ölüm oranları yüksek enfeksiyonlardır². HE gelişmiş ve gelişmekte olan ülkelerde hastanede yatış süresinde ve tedavi maliyetlerinde artışa yol açan, önemli bir morbidite ve mortalite nedenidir³ .

Yoğun bakım ünitelerindeki (YBÜ) hastalarda hastanede yatış sürelerinin uzun olması, profilaktik geniş spektrumlu antibiyotik kullanımı, fazla sayıda girişimsel işlem uygulanması gibi nedenlerle diğer birimlere kıyasla daha yüksek oranda ve daha dirençli hastane enfeksiyonları tespit edilmektedir ${ }^{4,5,6}$. YBÜ'de düzenli sürveyans çalışmalarının yapılması önem taşımaktadır. Bu çalışmalar sık rastlanan enfeksiyon etkenlerin tespit edilip bunların antibiyotik duyarlılıklarının saptanmasında ve bu sonuçlara bağlı olarak uygun ve etkili ampirik tedavilerde yol gösterici olmakta$\operatorname{dir}^{7}$.

$\mathrm{Bu}$ çalışmada hastanemiz erişkin ve çocuk yoğun bakım ünitelerinde yatan hastalarda santral sinir sistemi, kan ve santral venöz kateterle ilişkili enfeksiyonlara neden olan etkenlerin dağılımının incelenmesi amaçlanmıştır.

\section{GEREÇ ve YÖNTEM}

Hastanemiz yoğun bakımlarında Ocak 2016- Aralık 2020 tarihleri arasında yatan hastalarda gelişen ve hastane enfeksiyonu olarak değerlendirilen santral sinir sistemi, kan ve santral venöz kateterle ilişkili kan enfeksiyonları, kültüre dayalı surveyans yöntemi ile retrospektif olarak incelendi. Hastane enfeksiyonlarının takibi, kaydı ve incelenmesi enfeksiyon kontrol komitesi tarafından yürütülmüştür. Enfeksiyon kontrol hemşireleri ve enfeksiyon kontrol hekimlerinin günlük takipleri ile elde edilen veriler toplanmıştır.
Hastane kaynaklı enfeksiyon tanımı, Hastalık Kontrol ve Önleme Merkezi (CDC) kriterlerine göre yapılmıştır. Enfeksiyonlar hastaneye yatıştan 72 saat ve daha sonrasında saptanmışsa hastane kaynaklı olarak kabul edilmiştir.

HE geliştiği düşünülen hastalardan kan kültürü ile eş zamanlı enfeksiyon olduğu düşünülen odaklardan örnekler alınmıştır. Örnekler Mikrobiyoloji Laboratuvarında standart manuel ve otomatize yöntemler kullanılarak değerlendirilmiş ve elde edilen verilerden HE kriterlerine uyan hastalar kaydedilmiştir.

\section{Bakteri Tanımlama ve Duyarlılık Testleri}

Bakteriyemi şüphesi olan hastalardan alınan kan örnekleri ve santral sinir sistemi enfeksiyonu şüphesi ile gelen hastalardan alınan beyin omurilik sıvısı örnekleri kan kültürü şişeleri içinde laboratuvarımıza geldikten sonra $37^{\circ} \mathrm{C}$ 'de 5 gün boyunca BacT/Alert 3D (bioMérieux, Nurtingen, Germany) kan kültür sistemlerinde inkübe edilmiştir. Cihazın sinyal verdiği kan kültürü örnekleri \%5 koyun kanlı agar (BD Diagnostic Systems, USA), eozin metilen mavisi (EMB) agar (BD Diagnostic Systems, USA) ve çikolatalı agar (BD Diagnostic Systems, USA) ortamına ekildi. Bu ortamlar $35^{\circ} \mathrm{C}$ sıcaklıkta 20-24 saat inkübe edilmiştir. Üreyen mikroorganizma tanımlanmasında Gram boyama, oksidaz testi gibi konvansiyonel mikrobiyolojik yöntemler ile birlikte MALDI TOF MS (Bruker, Almanya) ve Phoenix (Becton Dickinson-Belçika) otomatize tanımlama sistemleri kullanılmıştır.

\section{BULGULAR}

Beş yıllık sürede Erişkin Yoğun Bakımlarda 25105, Yenidoğan Yoğun Bakım’da 6066, Çocuk Yoğun Bakım’da 1745 olmak üzere toplam 32916 hasta retrospektif olarak incelenmiştir. Hastaların $186(\% 0,6)$ 'sına laboratuvar tarafından doğrulanmış kan kültür enfeksiyonu, 474 (\%1.44)'üne santral venöz kateter enfeksiyonu, 18 (\%0.05)'ine menenjit tanısı konulmuştur. Santral venöz kateter enfeksiyon etkeni olarak sıklık sirasiyla 116 (\%24.5) C.parapsilosis, 98 (\%20.7) K.pneumoniae, 48 (\%10.1) Koagülaz Nega- 
J Biotechnol and Strategic Health Res. 2021;5(2):119-124

ŞAMLIOĞLU, ATALAY, Yoğun Bakım Ünitelerinde Hastane Enfeksiyonu Etkenlerinin Beș Yıllık Analizi

tif Staflokoklar tespit edilmiştir. Menenjit etkeni olarak 11 (\%61.1) K.pneumoniae, 2 (\%11,1) KNS bulunmuştur. Hastane enfeksiyonu olarak değerlendirilen kan kültürlerinde en sık KNS 40 (\%21.7) daha sonra K.pneumoniae 34 (\%18.5) ve C.parapsilosis 18 (\%9.8) saptanmıştır. Tablo 1' de enfeksiyon bölgesine göre etken mikroorganizma dağ1lımı, Figür 1, Figür 2, Figür 3’te mikroorganizma türlerine göre enfeksiyon etkenlerin sıklığı görülmektedir.

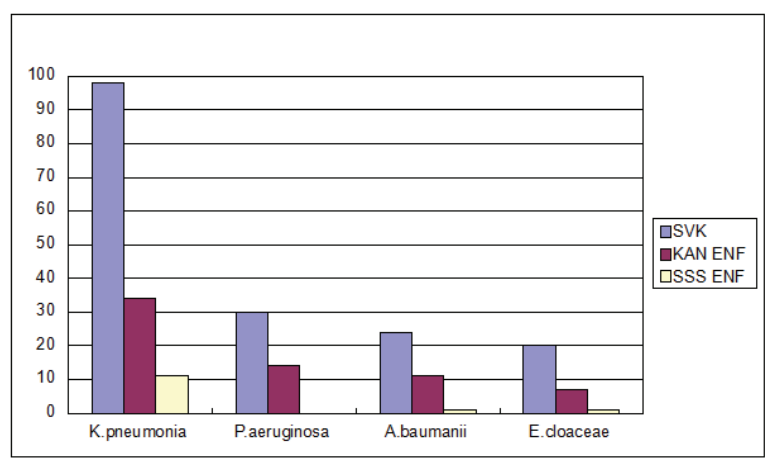

Figür 1: En sık HE Etkeni Gram Negatif Bakteri Sayıları

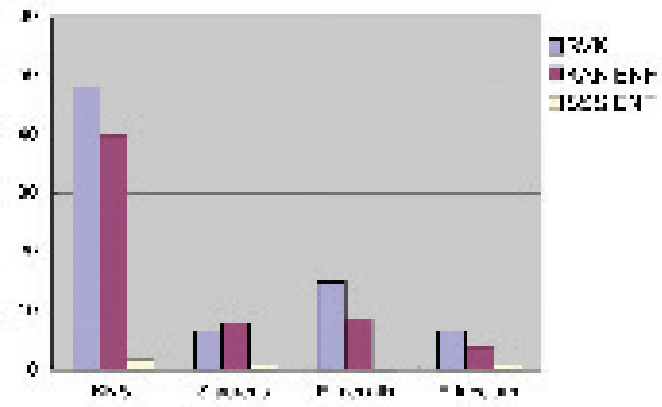

Figür 2: En Sık HE Etkeni Gram Pozitif Bakteri Sayıları

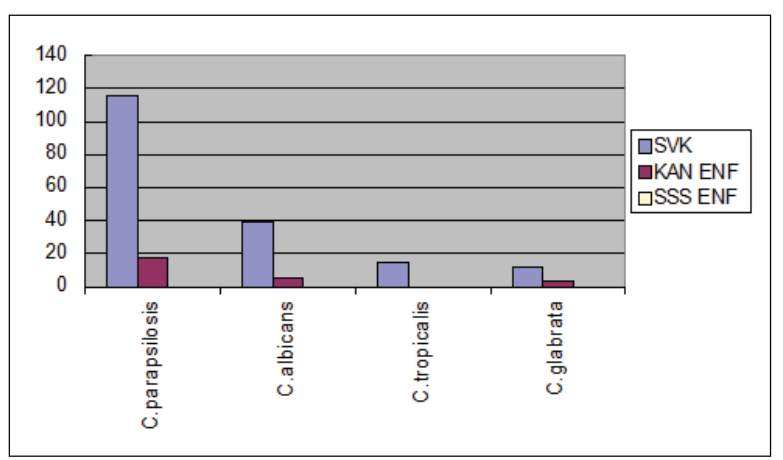

Figür 3: En Sık HE Etkeni Candida türleri

\begin{tabular}{|l|c|c|c|}
\hline \multicolumn{4}{|l|}{$\begin{array}{l}\text { Tablo } 1 \text { : Enfeksiyon Bölgesine Göre Etken Mikroorganizma } \\
\text { Dağllmı }\end{array}$} \\
\hline ETKEN & $\begin{array}{c}\text { Santral Venöz } \\
\text { Kateter }\end{array}$ & Kan Enf & $\begin{array}{c}\text { Santral Sinir } \\
\text { Sistemi Enf }\end{array}$ \\
\hline K.pneumoniae & $98(\% 20.7)$ & $34(\% 18.5)$ & $11(\% 61.1)$ \\
\hline K.oxytoca & $5(\% 1.1)$ & $5(\% 2.7)$ & $1(\% 5.5)$ \\
\hline P.aeruginosa & $30(\% 6.3)$ & $14(\% 7.6)$ & \\
\hline A.baumanii & $24(\% 5.0)$ & $11(\% 6.0)$ & $1(\% 5.5)$ \\
\hline A.lwoffi & $1(\% 0.2)$ & & \\
\hline B.cepacia & $1(\% 0.2)$ & & \\
\hline A.xylosoxidans & $1(\% 0.2)$ & $1(\% 0.5)$ & \\
\hline Citrobakter spp & $1(\% 0.2)$ & & \\
\hline E.aerogenes & $1(\% 0.2)$ & $2(\% 1.1)$ & \\
\hline E.cloaceae & $20(\% 4.2)$ & $7(\% 3.8)$ & \\
\hline E.coli & $8(\% 1.7)$ & $14(\% 7.6)$ & \\
\hline S.marcescens & $9(\% 4.9)$ & $3(\% 1.6)$ & \\
\hline M.morganii & $2(\% 0.4)$ & $2(\% 1.1)$ & \\
\hline S.maltophilia & $4(\% 0.8)$ & $1(\% 0.5)$ & \\
\hline S.aureus & $7(\% 1.5)$ & $8(\% 4.3)$ & $1(\% 5.5)$ \\
\hline KNS & $48(\% 10.1)$ & $40(\% 21.7)$ & $2(\% 11.1)$ \\
\hline E.faecalis & $15(\% 3.2)$ & $9(\% 4.9)$ & \\
\hline E.faecium & $7(\% 1.5)$ & $4(\% 2.2)$ & $1(\% 5.5)$ \\
\hline C.albicans & $39(\% 8.2)$ & $5(\% 2.7)$ & \\
\hline C.parapsilosis & $116(\% 24.5)$ & $18(\% 9.8)$ & \\
\hline C.krusei & $3(\% 0.6)$ & $1(\% 0.5)$ & \\
\hline C.tropicalis & $15(\% 3.2)$ & & \\
\hline C.glabrata & $12(\% 2.5)$ & $3(\% 1.6)$ & \\
\hline C.dubliniensis & $2(\% 0.4)$ & & \\
\hline Candida spp. & $2(\% 0.4)$ & & \\
\hline C.striatum & $2(\% 0.4)$ & & \\
\hline Providencia spp. & & $1(\% 0.5)$ & \\
\hline P.mirabilis & & & \\
\hline C.famata & & & \\
\hline C.laurentii & & & \\
\hline TOPLAM & & & \\
\hline
\end{tabular}

\section{TARTIŞMA}

Gelişen tıbbi teknoloji ve profesyonel ekipmanlar sayesinde son yıllarda yoğun bakım ünitelerinde bir çok hastanın yaşam süresinin uzaması sağlanmıştır. YBÜ’de takip edilen hastaların eşlik eden komorbid hastalıklarının ve metabolik sorunlarının bulunması, düşük immünitelerinin olması enfeksiyon gelişim riskini arttırmaktadır.. Bununla 
birlikte hastalarda invaziv işlemlerin daha fazla uygulanması, uzun süreli periferik ve santral venöz kateterizasyon, endotrakeal tüp kullanımı HE için olumsuz risk faktörleri olarak değerlendirilmektedir. ${ }^{9}$

İntravasküler kateterlerin YBÜ'lerinde yaygın kullanımı, kateterle ilişkili enfeksiyonların ortaya çıkmasına katkıda bulunan en önemli faktör olarak kabul edilmektedir. Özellikle santral venöz kateterler, bu enfeksiyonlara yol açabilen en yaygın kateter türleridir ${ }^{10}$.

Hastanede yatan hastalarda son 20 yılda fungal enfeksiyonların sıklığı belirgin şekilde artmıştır ${ }^{11}$. Candida türleri YBÜ'lerinde hastane enfeksiyonu kabul edilen kan enfeksiyonlarında \%8-15 oranlarında bildirilmiştir' ${ }^{12}$.Çocuklarda hastane kaynaklı kan akımı enfeksiyonu başlıca etkenleri arasında Candida spp. bildirilmiş ${ }^{13}$ Çalışmamızda yoğun bakım ünitelerinde tedavi alan 189 hastanın santral venöz kateterinde, 29 hastanın kan kültüründe Candida türleri izole edilmiştir.Santral venöz kateterde C.albicans 39 (\%8.2), C.parapsilosis 116 (\%24.5), C.tropicalis 15 (\%3.2), C.glabrata 12 (\%2.5), C.krusei 3 (\%0.6), C.dubliniensis $2(\% 0.4)$ bulunmuştur. Kan kültüründe ise C.albicans 5(\%2.7), C.parapsilosis 18 (\%9.8), C.glabrata 3 (\%1.6), C.krusei 1 (\%0.5) saptanmıştır.

Nozokomiyal enfeksiyonlarda enfeksiyon riskini artıran faktörler; hastaya ait faktörler, yapılan invaziv girişimler ve çapraz kontaminasyondur. Hasta yaşının birden küçük olması ve bir haftadan daha uzun hospitalizasyon nozokomiyal enfeksiyon riskini artırır ${ }^{14}$. HE'nda klinik önemi olan gram negatif bakteriler çoğunlukla Klebsiella pneumoniae, Escherichia coli, Pseudomonas aeruginosa ve Acinetobacter baumannii'dir ${ }^{15,16}$. Bu çalışmada da K.pneumoniae, Pseudomonas aeruginosa, Acinetobacter baumannii, E.cloaceae ve Escherichia coli en sık görülen gram negatif bakteriler olarak bulunmuştur.

Kan enfeksiyonları hızlı bir şekilde sepsis tablosuna ilerleyebilmeleri nedeniyle yoğun bakım hastalarında oldukça önem taşımaktadır. Vincent JL ve ark yaptığı çalışmada kan dolaşımı enfeksiyonlarında en sık etken olarak koagülaz negatif stafilokoklar (KNS) ve S. aureus bildirilmiştir ${ }^{17}$ Köksaldı ve ark.'nın çalışmasında kan dolaşımı enfeksiyonlarında gram-pozitif koklar, en sık etken olarak saptanmıştır ${ }^{18}$. Şahin A ve ark nöroloji yoğun bakımdaki kan enfeksiyonlarında \%57,1 oran ile en sık KNS, ardından Candida spp. \%28,5 etken bulmuşlardır ${ }^{19}$. Çalışmamızda KNS kan enfeksiyonlarında en sık görülen etken olup \%21.7, K.pneumoniae \%18.5 oranında bulunmuştur. Nonfermentatif grupta yer alan Pseudomonas aeruginosa ve Acinetobacter baumannii ise $\% 7.6$ ve $\% 6$ oranlarında görülmüştür.

Kan dolaşım enfeksiyonları çoğunlukla SVK ile ilişkili olup kateter varlığı sepsise gidişi hızlandırabilir. SVK kaynaklı kan dolaşım enfeksiyonları yüksek mortalite hızına sahiptir. Şenol A ve ark santral venöz kateter enfeksiyonlarında (SVK) en sık etken olarak A.baumanii 19 (\%30.6), K.pneumoniae 7 (\%11.3) bulmuştur ${ }^{20}$. Çalışmamızda K.pneumoniae'ya \%20.7, oranıyla ikinci sırada rastlanmıştır. Nonfermentatif grupta yer alan Pseudomonas aeruginosa ve Acinetobacter baumannii ise SVK enfeksiyonlarında \% 6.3 ve $\% 5$ oranlarında bulunmuştur. Avrupa'dan bildirilen çok uluslu bir çalışmada yoğun bakım ünitelerine 6 ayda yatan 710 olgudan 13'ünde kan enfeksiyonu $(\% 1,9)$, 21'inde santral kateter ilişkili $(\% 2,9)$ enfeksiyon saptandığ 1 bildirilmiştir. Görülme sıklığına göre enfeksiyon etkenleri olarak; KNS, Klebsiella spp, Staphylococcus aureus, Pseudomonas aeruginosa saptanmıştır ${ }^{21}$.

Çin'den yapılan çalışmada beş yıllık süre boyunca kateterle ilişkili kan dolaşım enfeksiyonu etkeni olarak saptanan en yaygın mikroorganizmalar KNS \% 44,6, Staphylococcus aureus $(\% 17,4)$, Klebsiella türleri $(\% 11,5)$ ve Acinetobacter türleri (\% 11.5) bulunmuştur ${ }^{22}$. İspanya'da, YBÜ’leri kan enfeksiyonu izolatları KNS (\% 24.4) ve Staphylococcus aureus (\%17.5) bulunmuştur ${ }^{23}$. Dünyada ve ülkemizde yapılan çalışmalar incelendiğinde çalışmamızda saptadığımız kan dolaşımı, santral venöz kateter ve santral sinir 
J Biotechnol and Strategic Health Res. 2021;5(2):119-124

sistemi sık görülen enfeksiyon etkenlerinin diğer çalışmalarla uyumlu olduğu görülmüştür.

Yoğun bakım ünitelerinde HE etken mikroorganizmaların üreme oranları ve antimikrobiyal duyarlılıklarını belirlemek, hem tedavi seçiminde yol göstermek hem de mortalite ve morbiditeyi azaltmak için önemlidir Antibiyotiklerin keşfi ve kullanımının yaygınlaşması ile birlikte dirençli bakterilerle gelişen HE’ları tüm dünyada gözlenen bir sorundur. Antibiyotiklere dirençli etkenlerin neden olduğu bu enfeksiyonlar, hem morbidite ve mortaliteyi arttırmakta hem de hastanede yatı̧s süresini uzatarak ciddi komplikasyonlara neden olabilmektedir.

\section{SONUÇ}

Çalı̧̧mamızda hastanemiz yoğun bakım ünitelerinde santral sinir sistemi, kan ve santral venöz kateterle ilişkili hastane enfeksiyonu etkenleri incelenmiştir. Sonuçlarımızı dünyada ve ülkemizde yapılan çalışmalarla karşılaştırdığımızda sık görülen enfeksiyon etkenlerinin diğer çalışmalarla uyumlu olduğu görülmüştür HE sıklığını azaltmak için Enfeksiyon Kontrol komitelerinin belirlediği sık rastlanan enfeksiyon etkeni patojenlerin yayılma ve bulaşmasına karşıllı alacağı tedbirlere, standart önlemlere ve el hijyenine uymak özellikle yoğun bakım birimlerinde gereksiz invaziv alet kullanımından kaçınmak gerekmektedir. HE etkenlerinin belirlenerek hastalara bunlara yönelik uygun ampirik antibiyotik başlanması ve gereksiz antibiyotik kullanımının engellenmesinin hastane enfeksiyon oranlarını düşereceği düşünülmektedir. 
J Biotechnol and Strategic Health Res. 2021;5(2):119-124

\section{References}

1. Eren F, Öngün G, Ural O ve ark. Nöroloji yoğun bakım ünitesinde bir ylllık hastane enfeksiyonu oranları: patojenik ve klinik değerlendirme. Turk J Neurol. 2017; 23(4): 205210. doi:10.4274/tnd.59002

2. Yalaki Z, Meral R, Yllmaz A ve ark. Çocuk yoğun bakım ünitesinde Acinetobacter enfeksiyonları. Ankara Eğt. Arș. Hast. Derg. 2018; 51(2): 98-103.

3. Eroğlu E. Nöroloji yoğun bakım ünitesinde gelișen hastane enfeksiyonlarının değerlendirilmesi. Turkiye Klinikleri J Intern Med. 2020;5(2):49-54. doi: 10.5336/intermed.2019-72948.

4. Kuzdan C, Soysal A, Culha G ve ark. Three-year study of health care-associated infections in a Turkish pediatric ward. J Infect Dev Ctries 2014:8(11):1415-1420.

5. Ok G, Gazi H, Tok D ve ark. Celal Bayar Üniversitesi Anestezi Yoğun Bakım Ünitesi’nde hastane infeksiyonlarının sürveyansı. Yoğun Bakım Dergisi 2007;7(4):452-457.

6. Anderson DJ, Podgorny K, Berríos-Torres SI et al. Strategies to prevent surgical site infections in Acute Care Hospitals: 2014 update.Infect Control Hosp Epidemiol 2014;35(6):605-627. doi: 10.1086/676022.

7. Inan A, Ozgultekin A, Akçay SS et al. Alterations in bacterial spectrum and increasing resistance rat in isolated microorganisms from device-associated infections in an Intensive Care Unit of a Teaching Hospital in Istanbul (2004-2010). Jpn J Infect Dis 2012;65(2):146-151.

8. Horan TC, Andrus M, Dudeck MA. CDC/NHSN surveillance definition of health careassociated infection and criteria for specific types of infections in the acute care setting. Am J Infect Control 2008;36(5):309-332. doi: 10.1016/j.ajic.2008.03.002.

9. Çelikel T. Dünyada ve Türkiye’de yoğun bakım uzmanlığı. Yoğun Bakım Dergisi 2001; 1(1): 5-9.

10. O'Horo JC, Maki DG, Krupp AE et al. Arterial catheters as a source of bloodstream infection: A systematic review and meta-analysis. Crit Care Med 2014; 42(6):1334-1339. doi: 10.1097/CCM.0000000000000166.

11. Corona A, Bertolini G, Lipman J et al. Antibiotic use and impact on outcome from bacteraemic critical illness: The Bacteraemia Study in Intensive Care (BASIC). J Antimicrob Chemother 2010 ;65(6):1276-1285. doi: 10.1093/jac/dkq088.

12. Prowle JR, Echeverri JE, Ligabo EV et al. Acquired bloodstream infection in the intensive care unit: Incidence and attributable mortality. Crit Care 2011; 15(2):R100. doi: 10.1186/ cc10114.
13. Becerra MR, Tantaleán JA, Suárez VJ et al. Epidemiologic surveillance of nosocomial infections in a Pediatric Intensive Care Unit of a developing country. BMC Pediatrics 2010;10:66-75. doi: 10.1186/1471-2431-10-66.

14. Özçetin M, Saz EU, Karapınar B et al. Hastane Enfeksiyonları; Sıklığı ve Risk Faktörleri. Çocuk Enf Derg 2009; 3: 49-53.

15. Nicasio AM, Kuti JL and Nicolau DP. The current state of multidrug-resistant gram-negative bacilli in North America. Pharmacotherapy 2008; 28(2): 235-249. doi: 10.1592/ phco.28.2.235.

16. Nordmann P, Cuzon G, Naas T. The real threat of Klebsiella pneumoniae carbapenemase-producing bacteria. Lancet Infect Dis. 2009; 9(4): 228-236. doi: 10.1016/S14733099(09)70054-4.

17. Vincent JL, Rello J, Marshall J et al. International study of the prevalence and outcomes of infection in intensive care units. Jama 2009; 302(21): 2323-2329. doi: 10.1001/ jama.2009.1754.

18. Köksaldı MV, Evirgen Ö, Yula E. Mustafa Kemal Üniversitesi Tıp Fakültesi Yoğun Bakım Ünitesỉnde 2011 yllında sağlık hizmeti ile ilișkili infeksiyonların değerlendirilmesi. AN KEM Derg. 2012; 26(3): 137-142.

19. 19) Şahin AR, Ylldız BT, Aktemur A ve ark. Bir üniversite hastanesi nöroloji yoğun bakım ünitesinde gelişen enfeksiyonların değerlendirilmesi. J Contemp Med 2019; 9(1): 43-47. doi: $10.16899 /$ gopctd. 481366 .

20. Șenol A, Balin ŞÖ.Yoğun bakım ünitelerinde sık görülen enfeksiyonlar, gram-negatif mikroorganizmalar, antibiyotik direnci. KSÜ Tip Fak Der 2021;16(1): 35-39.

21. Raymond J, Aujard Y. Nosocomial infections in pediatric patients: a European, multicenter prospective study. European Study Group. Infect Control Hosp Epidemiol 2000; 21(4): 260-263. doi: 10.1086/501755.

22. Deng S, Feng S, Wang W et al. Bacterial distribution and risk factors of nosocomial blood stream infection in neurologic patients in the Intensive Care Unit. Surg Infect(Larchmt) 2019; 20 (1): 25-30. doi: 10.1089/sur.2018.085.

23. Valle's J, Leo'n C, Alvarez-Lerma F. Nosocomial bacteremia in critically ill patients: A multicenter study evaluating epidemiology and prognosis. Spanish Collaborative Group for infections in intensive Care Units of Sociedad Espanola de Medicina Intensivay Unidades Coronarias (SEMIUC). Clin Infect Dis 1997; 24(3): 387-395. doi: 10.1093/clinids/24.3.387. 